\title{
Graphene-Coated Sensor Yarn for Composite Preforms ${ }^{\dagger}$
}

\author{
Anura Fernando *, Sammia Ali, Sirui Tan and Guanliang He \\ Department of Materials, School of Natural Sciences, Faculty of Science and Engineering, The University of \\ Manchester, Manchester M13 9PL, UK; sammia.ali@postgrad.manchester.ac.uk (S.A.); \\ sirui.tan@postgrad.manchester.ac.uk (S.T.); guanliang.he@postgrad.manchester.ac.uk (G.H.) \\ * Correspondence: anura.fernando-2@manchester.ac.uk; Tel.: +44-0161-306-3753 \\ + Presented at the International Conference on the Challenges, Opportunities, Innovations and Applications \\ in Electronic Textiles (E-Textiles 2019), London, UK, 12 November 2019.
}

Published: 20 January 2020

Keywords: graphene coated sensor yarn; mettalic

There is extensive research to demonstrate that textile fibre reinforced composites can produce high strength and stiffness at a low weight allowing them to become excellent candidates for applications requiring improved strength and lighter structures compared to their metallic counterparts. Despite these impressive properties, textile composites are susceptible to damage that prevails from matrix cracking, delamination and finally damage to their reinforcing preforms. The initiation and the progression of damage mechanism, within textile composites, is a complex phenomenon that is very difficult to predict; due to this, great effort is currently being made towards incorporating multiphysical parameter sensing capabilities into textile preforms. In this regard, the electroconductive sensing yarns produced through the coating with recently discovered twodimensional (2D) nanomaterials have emerged as a promising way to monitor the health and integrity of various engineering materials including composites for healthcare, sportswear, space and military applications. Among these sensor properties imparting coating materials, graphene has become one of the most investigated materials in recent times. The research presented discusses some of the recent achievements in producing graphene-coated sensing fibres for incorporation into textile preforms.

As early as 1998, researchers have been developing sensing devices to monitor various physical signals for healthcare, military and space exploration [1]. The sharp growth of textile-based sensor technology can be generally attributed to the advances mentioned below:

(1) Micro/nano electronic devices that integrate into fibre, yarn and fabrics, converting the textile materials into advanced electronics capable of sensing and information transmission without compromising the comfort of the wearer [2]. Likewise, smaller and flexible power sources for E-textile applications have emerged while energy-harvesting power electronics are already under development by companies [3].

(2) Conductive threads and yarns, usually composed of stainless steel, carbon yarn or conductive silver, with a nylon core, have become widely available [4]. The properties of such threads and their applications in sensing and signal transmission lines for E-textile applications have been documented, facilitating their selection and implementation in products where textile structures are used.

(3) Textile-based components including capacitors, resistors and transistors have been devised, allowing the full integration of simple circuits/networks onto fibre-based structures. Piezoelectric/piezo-resistive textiles have also emerged, promoting the development of a full range of yarn- and fabric-based sensors [5]. At the present time much work is underway to integrate fibre 
yarn and fabric-based sensors into various materials including their integration in textile preforms for composites.

The popularity of fibre-reinforced composite structures in engineering fields is due to their light weight as well as high strength and stiffness [6-9]. However, sometimes during their use, composite structures made of resin matrix and a textile reinforcing preform experience matrix cracking; this is a failure mechanism that can lead to delamination between the fibres and the resin resulting in the failure of the composite itself. In order to avoid resin matrix delamination and fibre breakages in composites, continuous long-duration monitoring is essential. In this case, the availability of electroconductive textile material together with the advanced textile preform manufacturing technologies available have become very good facilitators for integrating sensory capability into fibre-based laminated composites. These technologies allow us to develop composites with long-term continuous monitoring of composite material, panels or products ensuring a high level of safety to the application [10]. The concept of creating a conductive matrix is also investigated by using other fillers such as graphene, carbon black, carbon nanoparticle as well as metallic nanoparticles [11-14]. Several other approaches are also used as resistive sensors which include electro-conductive yarn, as well as coated and thin-film-based sensors [15-19].

Considering textile preforms used in laminated composites, as mentioned above, there are usually two methods to introduce sensors: using micro/nano electronic devices in the preform structure individually or in a network, or through the use of electroconductive material coated fibres/yarn as single sensory devices or in a textile structure to form a sensor network. Both methods have their own advantages and disadvantages limiting their usage in different applications. This is mainly due to conditions such as electrical components that can act as a foreign entity within a resin matrix which could significantly affect the mechanical properties of the reinforced structure [20-22]. In the production of coated electroconductive sensory or transmission yarn, the particle size, viscosity, surface tension and concentration of the electroconductive material used, uniformity of the coated film as well as the electroconductivity and mechanical performance of the conductive material are of high importance [23].

In constructing textile sensors in composites, the use of metallic/non-metallic fibres is popular due to their high standard of manufacture reliability as electroconductive textile products [24]. Among the available metallic/non-metallic electroconductive yarn is copper, stainless steel, carbon fibre and silver, although highly expensive, due to the low electrical resistance shown; silver-coated polymeric yarn has a wider range of applications [25]. Continuous filament carbon fibres are generally of very high resistance and do not present enough signal magnification in textile sensors constructed in preforms.

With the recent discovery of $2 \mathrm{D}$ and $3 \mathrm{D}$ materials in the field of materials, electroconductive materials with very high conductivity were reported. Among these, graphene is a two-dimensional atomic sheet of $\mathrm{sp}^{2}$-hybridized carbon atoms that displays outstanding physical properties including high carrier mobility up to $350,000 \mathrm{~cm}^{2} /(\mathrm{V} \mathrm{s})$, high optical transparency up to $97.7 \%$ for single-layer graphene, high mechanical strength with Young's modulus of $1 \mathrm{TPa}$ and fracture strength of $130 \mathrm{GPa}$, and thermal stability [26]; it was reported as one of the materials with the capability to be very effective in the E-textiles field. This research investigates the relative sensory performance of silvercoated polymeric yarn, carbon fibre yarn, stainless steel yarn and graphene-coated yarn as a sensor material. In addition, in order to find out the electroconductivity of sensor yarn post resin infusion, an experiment was carried out by infusing a glass fibre preform, integrated with silver- and graphene-coated yarn, with Ecoflex resin.

The sensor yarn was integrated in the textile preform as a laid-in yarn. This research further investigates the performance of the sensor yarn inside the composite due to the penetration of resin in between the electroconductive fibres and knitted structure binding areas.

As revealed, the filaments of stainless steel (SS) yarn and carbon yarn demonstrate a higher degree of compactness as compared to coated yarn, namely silver-coated polymeric yarn and graphene-coated cotton yarn. Although the continuous filament SS yarn and carbon fibre yarn show similarities in appearance, the SS yarn is more robust while the carbon yarn is susceptible to fibre 
breakages. The preliminary investigation into developing rigid sensing preforms suggests that the laid-in sensor designs were suitable for the applications requiring a lower degree of flexibility.

Funding: This research received no external funding.

Acknowledgments: The authors would like to acknowledge the contribution made by Edward Lay for the fabrication of SS integrated samples.

Conflicts of Interest: The authors declare no conflicts of interest.

\section{References}

1. Park, S.; Mackenzie, K.; Jayaraman, S. Framework for Personalized Mobile Information Processing (PMIP). In Proceedings of the 2002 Design Automation Conference (IEEE Cat. No.02CH37324), New Orleans, LA, USA, 10-14 June 2002; pp. 10-14.

2. Meoli, D.; May-Plumlee, T. Interactive electronic textile development: A review of technologies. Technol. Manag. 2012, 2, 1-12.

3. Post, E.R.; Orth, M.; Russo, R.R.; Gershenfeld, N. E-broidery: Design and fabrication of textile-based computing. IBM Syst. J. 2000, 39, 840-860.

4. Cottet, D.; Grzyb, J.; Kirstein, T.; Tröster, G. Electrical characterization of textile transmission lines. IEEE Trans. Adv. Packag. 2003, 26, 182-190.

5. Orth, M. Defining Flexibility and Sewability in Conductive Yarns. MRS Proc. 2002, 736, D1.4.

6. Hasan; B, M.M.; Cherif, C.; Matthes, A. Early prediction of the failure of textile-reinforced thermoplastic composites using hybrid yarns. Compos. Sci. Technol. 2012, 72, 1214-1221.

7. Roscher, K.U.; Fischer, W.-J.; Landgraf, J.; Pfeifer, G.; Starke, E. Sensor Networks for Integration into Textile-Reinforced Composites. In Proceedings of the 14th International Conference on Solid-State Sensors, Actuators and Microsystems, Lyon, France, 10-14 June 2007; pp. 1589-1592.

8. Staab, G.H. Introduction to Composite Materials. In Laminar Composites; Staab, G.H., Ed.; Butter Worth Heinemann (Member of Elsevier Group): Oxford, UK, 1999; First Edition, pp. 1-16; ISBN 978-0-7506-7124-8.

9. Strong, A.B. Damage prevention and repair. In Fundamentals of Composites Manufacturing-Materials, Methods, and Applications; Society of Manufacturing Engineers (SME): Dearborn, MI, USA, 2008; pp. 481504.

10. Diamanti, K.; Soutis, C. Structural health monitoring techniques for aircraft composite structures. Prog. Aerosp. Sci. 2010, 46, 342-352.

11. Galao, O.; Baeza, F.J.; Zornoza, E.; Garcés, P. Strain and damage sensing properties on multifunctional cement composites with CNF admixture. Cem. Concr. Compos. 2014, 46, 90-98.

12. Johnson, M.T.; Fullwood, D.T.; Hansen, G. Strain monitoring of carbon fiber composite via embedded nickel nano-particles. Compos. Part B Eng. 2012, 43, 1155-1163.

13. Chiacchiarelli, L.M.; Rallini, M.; Monti, M.; Puglia, D.; Kenny, J.M.; Torre, L. The role of irreversible and reversible phenomena in the piezoresistive behavior of graphene epoxy nanocomposites applied to structural health monitoring. Compos. Sci. Technol. 2013, 80, 73-79.

14. Nanni, F.; Ruscito, G.; Puglia, D.; Terenzi, A.; Kenny, J.M.; Gusmano, G. Effect of carbon black nanoparticle intrinsic properties on the self-monitoring performance of glass fibre reinforced composite rods. Compos. Sci. Technol. 2011, 71, 1-8.

15. Nauman, S.; Lapreyonnie, P.; Cristian, I.; Boussu, F.; Koncar, V. In Situ Strain Sensing in Three Dimensional Woven Preform Based Composites Using Flexible Textile Based Sensors. In Proceedings of the 10th International Conference on Textile Composites, Lille, France, 26-28 October 2010; Binetruy, C., Boussa, F., Eds.; DEStech Publicaions: Lancaster, PA, USA, 2010; p. 363.

16. Zhao, H.; Zhang, Y.; Bradford, P.D.; Zhou, Q.; Jia, Q.; Yuan, F.-G.; Zhu, Y. Carbon nanotube yarn strain sensors. Nanotechnology 2010, 21, 305502.

17. Rausch, J.; Mader, E. Health monitoring in continuous glass fibre reinforced thermoplastics: Manufacturing and application of interphase sensors based on carbon nanotubes. Compos. Sci. Technol. 2010, 70, 1589-1596.

18. Nasir, M.A., et al. Smart sensing layer for the detection of damage due to defects in a laminated composite structure. Journal of Intelligent Material Systems and Structures 2014, doi: 10.1177/1045389x14554138

19. Mouritz, A.P.; Bannister, M.K.; Falzon, P.J.; Leong, K.H. Review of applications for advanced threedimensional fibre textile composites. Compos. Part A Appl. Sci. Manuf. 1999, 30, 1445-1461. 
20. Hufenbach, W.; Adam, F.; Fischer, W.J.; Kunadt, A.; Weck, D. Mechanical behaviour of textile-reinforced thermoplastics with integrated sensor network components. Mater. Des. 2011, 32, 4931-4935.

21. Masmoudi, S.; El-Mahi, A.; El-Guerjouma, R. Structural Integrity of Laminated Composite with Embedded Piezoelectric Sensors. In Design and Modeling of Mechanical Systems - II; Chouchane, M., Fakhfakh, T., Daly, H., Aifaoui, N., Chaari, F., Eds.; Springer: Cham, Switzerland, 2015; pp. 673-680.

22. Konka, P.H.; Wahab, M.; Lian, K. The effects of embedded piezoelectric fiber composite sensors on the structural integrity of glass-fiber-epoxy composite laminate. Smart Mater. Struct. 2012, 21, 015016.

23. Berzowska, J. Electronic Textiles: Wearable Computers, Reactive Fashion, and Soft Computation. Textile 2005, 3, 58-75.

24. Alagirusamy, R.; Eichhoff, J.; Gries, T.; Jockenhoevel, S. Coating of conductive yarns for electro-textile applications. J. Text. Inst. 2013, 104, 270-277.

25. Shieldex ${ }^{\circledR}$ Produced by Statex. Conductive Yarns/Threads Available online: http://www.shieldextrading.net/products/yarns-threads/ (assessed on 13 January 2020).

26. Taniselass, S.; Arshad, M.K.M.; Gopinath, S.C.B. Graphene-based electrochemical biosensors for monitoring noncommunicable disease biomarkers. Biosens. Bioelectron. 2019. doi:10.1016/j.bios.2019.01.047.

(C) 2020 by the authors. Licensee MDPI, Basel, Switzerland. This article is an open access article distributed under the terms and conditions of the Creative Commons Attribution (CC BY) license (http://creativecommons.org/licenses/by/4.0/). 